\title{
Impact of mitral valve treatment choice on mortality according to aetiology
}

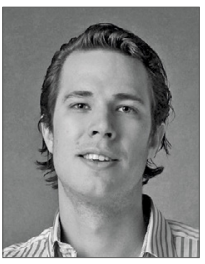

Friso Kortlandt ${ }^{1 *}$, MD; Juliette Velu², MSc; Remco Schurer ${ }^{3}, \mathrm{MD}$;

Ben Van den Branden ${ }^{4}, \mathrm{MD}, \mathrm{PhD}$; Berto Bouma², MD, PhD; Johannes Kelder ${ }^{1}, \mathrm{MD}, \mathrm{PhD}$;

Frank Eefting ${ }^{1}, \mathrm{MD}$; Martin Swaans ${ }^{1}, \mathrm{MD}, \mathrm{PhD}$; Benno Rensing ${ }^{1}, \mathrm{MD}, \mathrm{PhD}$;

Jan Baan Jr², MD, PhD; Jan Van der Heyden ${ }^{1}$, MD, PhD

1. St. Antonius Hospital, Nieuwegein, the Netherlands; 2. Academic Medical Center, Amsterdam, the Netherlands; 3. University Medical Center, Groningen, the Netherlands; 4. Amphia Hospital, Breda, the Netherlands

This paper also includes supplementary data published online at: http://www.pcronline.com/eurointervention/150th issue/299

\section{KEYWORDS}

- clinical research

- death

- mitral regurgitation

- mitral valve repair

\section{Abstract}

Aims: Treatment strategies of high-risk patients with mitral regurgitation (MR) differ between disease based on functional and disease based on degenerative origin. In the present study, we aimed to evaluate the effect of surgical, percutaneous, or conservative treatment of MR according to MV mechanism, for high-risk patients.

Methods and results: Survival outcomes of MitraClip, surgical, or conservative strategies were compared for 688 high-risk patients with functional MR and 275 with degenerative MR. Cox regression and propensity analyses were used to correct for differences in baseline characteristics. For functional MR, conservative treatment proved to have a higher mortality hazard when compared to MitraClip treatment (hazard ratio [HR] $1.79,95 \%$ confidence interval [CI]: 1.34 to $2.39, \mathrm{p}<0.001$ ), while there was no significant difference in mortality hazard between MitraClip and surgery (HR 0.86, 95\% CI: 0.54 to $1.38, \mathrm{p}=0.541$ ). For degenerative MR, no clear significant benefit was found when comparing MitraClip to conservative and surgical treatment.

Conclusions: High-risk patients with symptomatic functional MR have reduced mortality when undergoing MitraClip intervention, compared to those receiving conservative treatment. 


\section{Abbreviations}

DMR degenerative mitral regurgitation

ESII EurOSCORE II

FMR functional mitral regurgitation

LVEF left ventricular ejection fraction

MR mitral regurgitation

MV mitral valve

PH pulmonary hypertension

SPAP systolic pulmonary artery pressure

STS Society of Thoracic Surgeons

\section{Introduction}

\section{BACKGROUND}

The population of patients with mitral regurgitation (MR) is inhomogeneous. This is partially the result of the different mechanisms that lie at the base of this disease, each being associated with different comorbidity profiles. The aetiology of MR may be divided roughly into primary/organic or degenerative MR (DMR) in which the valve apparatus itself is diseased, and secondary or functional MR (FMR) in which mitral valve (MV) dysfunction is secondary to left ventricular disease ${ }^{1}$. Also, a distinction among patients can be made based on the level of assessed surgical risk ${ }^{2}$. Hence a "typical MR patient" is nonexistent and consequently no "one size fits all" treatment is available.

Editorials, see page 1710 and page 1713

\section{CONTEMPORARY KNOWLEDGE}

Contemporary ESC (2017) and AHA/ACC (2017) guidelines recommend choosing between surgery, percutaneous, and conservative treatment based on symptom burden, estimated surgical risk, and MV aetiology ${ }^{3,4}$. Surgical repair/replacement is the gold standard if prognosis benefit is to be expected, if MV repair/replacement is assessed as technically feasible, and if patient risk is not too high. High-risk patients with DMR may be considered for percutaneous therapy, of which MitraClip is currently the most widely used, if surgery is not warranted. For high-risk patients with FMR, a similar strategy is recommended only by the ESC guidelines, whereas the AHA/ACC guidelines do not mention percutaneous treatment for such patients. Medical treatment should be considered as appropriate in both populations ${ }^{3,4}$. The recommendations for MitraClip in high-risk patients with FMR is based on one one-arm observational study ${ }^{5}$, while publications which compared treatment of high-risk patients with MitraClip to more established therapeutic options for survival outcome remain scarce ${ }^{6-8}$. This is also true for specific subpopulations based on MV aetiology ${ }^{9-12}$.

\section{HYPOTHESIS}

In the present study we aimed to evaluate the effect of surgical, percutaneous, or conservative treatment of MR according to MV mechanism, for high-risk patients.

\section{Methods \\ PATIENT SELECTION}

Previously acquired data were used ${ }^{13}$. In short, data were gathered retrospectively from 1,036 high-risk patients with moderate-severe (grade 3/4) or severe (grade 4/4) symptomatic $\mathrm{MR}^{8}$. Patients from four centres were included. Between January 2009 and April 2016, 568 consecutive patients were treated using the MitraClip ${ }^{\circledR}$ (Abbott Vascular, Santa Clara, CA, USA) (Supplementary Table 1A). Control groups comprising 173 surgically treated patients (Supplementary Table 1B) and 295 conservatively treated patients (Supplementary Table 1C) were included. Patients from the two control groups were selected based on timing of MR diagnosis (for each centre, a selection period of two years prior to first MitraClip was used ranging from January 2007 to June 2012) and the high-risk criteria used by the Heart Team ${ }^{8,13}$. Patients with a logistic EuroSCORE (LES) $\geq 20 \%$, age $\geq 80$ years, left ventricular ejection fraction (LVEF) $<30 \%$, previous cardiac surgery, pulmonary hypertension, renal insufficiency (defined as glomerular filtration rate $<45 \mathrm{ml} / \mathrm{min} / 1.73 \mathrm{~m}^{2}$ ), underweight or severe overweight, previous chest radiation, chronic obstructive pulmonary disease and emphysema, porcelain aorta, or frailty were deemed high-risk. Only patients who had previously been judged as having either DMR or FMR were used for the current analyses, while patients with mixed (both degenerative and functional) MR were excluded.

\section{VARIABLES}

Surgical risk scores were determined by using online calculators (www.euroscore.org, riskcalc.sts.org). Renal insufficiency was defined as an estimated glomerular filtration rate $<45 \mathrm{ml} /$ $\min / 1.73 \mathrm{~m}^{2}$. The presence of pulmonary hypertension $(\mathrm{PH})$ was determined by using echocardiographic estimated systolic pulmonary artery pressure (SPAP), which was derived from tricuspid regurgitation gradient and estimated right atrial pressure. SPAP was subsequently categorised into "no $\mathrm{PH}$ " (unmeasurable or SPAP $<31 \mathrm{mmHg}$ ), "moderate PH" (SPAP $\geq 31$ and $<56 \mathrm{mmHg}$ ), or "severe PH" (SPAP $\geq 56 \mathrm{mmHg}$ ). All other characteristics were retrospectively obtained from patient files ${ }^{13}$. All-cause mortality data were collected by consulting the governmental death registry using social security numbers.

\section{STATISTICAL ANALYSIS}

Continuous variables are presented as mean $\pm \mathrm{SD}$, discrete variables as proportions. Comparisons between groups were carried out by using the one-way ANOVA test between groups for parametric data, with subsequent use of the Tukey honest significant difference post hoc test. Ordinal data were compared using the Kruskal-Wallis H and Dunn's multiple comparison tests while nominal data were compared using the chi-square test with Bonferroni adjustment.

For survival analysis, Kaplan-Meier estimates were created whereas comparisons were performed using log-rank statistics. We used a univariate Cox proportional hazards model to identify predictors of mortality. To counter imbalances in baseline differences and identify independent predictors, we used a manual backwards stepwise selection of significant variables. Baseline variables that had a significance of $p<0.10$ in univariate analysis were entered 
into the multivariate model, with the exception of surgical risk scores. SPSS, Version 24.0 (IBM Corp., Armonk, NY, USA) was used for basic analyses. Additionally, we tried to reduce confounding influences with propensity weighting and by using all variables with a $\mathrm{p}<0.05$ in the Cox model. For the statistical analyses regarding the propensity score, we used the R statistical program (www.r-project.org) version 3.3 (R Foundation for Statistical Computing, Vienna, Austria). P-values $<0.05$ (two-tailed) were considered statistically significant.

\section{Results \\ FUNCTIONAL MITRAL REGURGITATION}

\section{BASELINE}

Six hundred and eighty-eight (688) patients had FMR. Mean age was $72.0 \pm 11.2$ years, EuroSCORE II (ESII) was 7.4 \pm 6.8 , and LVEF was $33.1 \pm 13.1 \%$. Three hundred and sixty-five (365) patients underwent MitraClip treatment (63\% one clip, 34\% two clips, $3 \%$ three clips). Post-interventional MR grade was less than $3 / 4$ in $97 \%$. Respectively, 95 and 228 patients received surgical therapy ( $80 \%$ repair, $20 \%$ replacement) and conservative therapy (59\% of whom were on beta-blockers, $59 \%$ on ACE inhibitors or angiotensin II receptor blockers, $51 \%$ on aldosterone antagonists and $89 \%$ on diuretics). The treatment groups differed significantly (Table 1). MitraClip patients were older than patients treated by surgical intervention (mean 72.8 versus 67.5 years) but of similar age compared to conservatively treated patients (mean 72.8 versus 72.6 years). Surgical risk scores were highest in the MitraClip group, with a significantly higher ESII compared to surgically and conservatively treated patients (mean 8.9 versus 4.7 and 6.1, respectively). Although MitraClip patients in general were shown to have the least favourable comorbidity profile, LVEF was significantly lower in patients who underwent conservative management (mean $33.0 \%$ versus $29.8 \%$ ).

\section{SURVIVAL}

Median follow-up of FMR patients was 2.8 (IQR 1.3-5.1) years. For MitraClip patients, follow-up was 2.4 (IQR 1.2-3.6) years. For surgically and conservatively treated patients this was 5.2 (IQR 3.0-6.4) and 3.6 (IQR 1.1-6.1) years, respectively. During three-year follow-up, $122(33 \%)$ patients who underwent MitraClip therapy died. There were 22 (23\%) and 102 (45\%) observed deaths in the surgery and conservative groups, respectively. Log-rank testing showed a significantly different mortality estimate of $\mathrm{p}=0.001$ (Figure 1). Nominal comparisons using logrank testing revealed significant differences between MitraClip and surgery $(p=0.011)$ and between MitraClip and conservative treatment $(p=0.048)$. Baseline characteristics associated with mortality outcome were: treatment option, age, body mass index, atrial fibrillation, chronic obstructive pulmonary disease (COPD), myocardial infarction, coronary artery bypass grafting, pacemaker, renal insufficiency, LES, ESII, Society of Thoracic Surgeons (STS) score, New York Heart Association class, and PH. A Cox multivariate prediction model including 683 patients



Figure 1. Kaplan-Meier survival estimate of patients with functional mitral regurgitation.

proved that conservative treatment had a higher mortality hazard when compared to MitraClip treatment (HR 1.79, 95\% CI: 1.34 to $2.39, \mathrm{p}<0.001$ ), while there was no significant difference in mortality hazard between MitraClip and surgery (HR 0.86, 95\% CI: 0.54 to $1.38, \mathrm{p}=0.541$ ) (Table 2).

Propensity weighting resulted in an HR of 1.59 (95\% CI: 1.18 to $2.13, \mathrm{p}=0.002$ ) for conservative treatment compared with MitraClip, and an HR of 1.16 (95\% CI: 0.45 to $2.99, \mathrm{p}=0.77$ ) for MitraClip compared with surgery.

\section{DEGENERATIVE MITRAL REGURGITATION}

\section{BASELINE}

There were 275 patients who were identified with DMR. Patients had a mean age of 75.5 \pm 9.9 years, an ESII of $5.5 \pm 5.1$, and an LVEF of $48 \pm 13.6 \%$. One hundred and sixty-five (165) patients received MitraClip treatment (56\% one clip, 38\% two clips, $6 \%$ three clips). Reduction of MR to less than 3/4 was achieved in $80 \%$. Sixty-six (66) patients received surgical treatment (69\% repair, 31\% replacement) and 44 conservative treatment. Similar to the FMR cohort, there were significant baseline differences between the treatment groups (Supplementary Table 2). Remarkably, while MitraClip patients scored significantly higher with surgical risk scores when compared to those in the surgically and conservatively treated groups (mean ESII of 6.5 versus 3.8 and 4.4, respectively) and were older compared to surgically treated patients (mean 75.7 versus 71.4 years), their age was lower compared to conservatively treated patients (mean 75.7 versus 80.8 years). Nonetheless, MitraClip patients had worse comorbidity profiles and LVEF was significantly lower compared to the control groups (mean LVEF $43.7 \%$ versus $54.1 \%$ and $52.8 \%$ ). 
Table 1. Functional mitral regurgitation, baseline characteristics.

\begin{tabular}{|c|c|c|c|c|c|}
\hline \multicolumn{2}{|c|}{ Variable } & $\begin{array}{l}\text { MitraClip } \\
\text { N=365 }\end{array}$ & $\begin{array}{c}\text { Surgery } \\
N=95\end{array}$ & $\begin{array}{l}\text { Conservative treatment } \\
\qquad \mathrm{N}=228\end{array}$ & $p$-value \\
\hline \multicolumn{2}{|l|}{ Age, years } & $72.8( \pm 10.8)$ & $67.5( \pm 9.5)$ & $72.6( \pm 11.9)$ & $<0.001^{1,3}$ \\
\hline \multicolumn{2}{|l|}{ Male } & $218(60)$ & $48(51)$ & $127(56)$ & 0.212 \\
\hline \multicolumn{2}{|l|}{$\mathrm{BMI}, \mathrm{kg} / \mathrm{m}^{2}$} & $26.1( \pm 4.3)$ & $27.6( \pm 5.3)$ & $26.1( \pm 4.4)$ & $0.015^{1,3}$ \\
\hline \multicolumn{2}{|l|}{ HT } & $168(46)$ & $57(60)$ & $97(43)$ & $0.012^{1,3}$ \\
\hline \multicolumn{2}{|l|}{ DM } & 85 (23) & $29(31)$ & $53(24)$ & 0.305 \\
\hline \multicolumn{2}{|l|}{$\mathrm{AF}$} & $204(56)$ & $35(37)$ & 87 (39) & $<0.001^{1,2}$ \\
\hline \multicolumn{2}{|l|}{ COPD } & $72(20)$ & 18 (19) & $49(22)$ & 0.574 \\
\hline \multicolumn{2}{|l|}{ CAD } & $223(61)$ & $46(48)$ & $110(49)$ & 0.0032 \\
\hline \multicolumn{2}{|l|}{$\mathrm{MI}$} & $162(45)$ & $25(26)$ & $76(34)$ & $0.001^{1,2}$ \\
\hline \multicolumn{2}{|l|}{$\mathrm{PCl}$} & 115 (32) & $11(12)$ & $33(15)$ & $<0.001^{1,2}$ \\
\hline \multicolumn{2}{|l|}{ CABG } & $126(35)$ & $14(15)$ & $35(16)$ & $<0.001^{1,2}$ \\
\hline \multicolumn{2}{|l|}{ CVA } & $55(15)$ & $7(7)$ & 39 (17) & 0.067 \\
\hline \multicolumn{2}{|l|}{ PM } & $128(35)$ & $11(12)$ & $25(11)$ & $<0.001^{1,2}$ \\
\hline \multicolumn{2}{|l|}{ CRT } & $62(17)$ & $1(1)$ & $10(4)$ & $<0.001^{1,2}$ \\
\hline \multicolumn{2}{|l|}{$\mathrm{RI}^{*}$} & $132(37)$ & $11(13)$ & $54(32)$ & $<0.001^{1,3}$ \\
\hline \multicolumn{2}{|l|}{ LES } & $21.6( \pm 15.4)$ & $12.2( \pm 8.5)$ & $19.4( \pm 14.2)$ & $<0.001^{1,3}$ \\
\hline \multicolumn{2}{|l|}{ ESII } & $8.9( \pm 7.8)$ & $4.7( \pm 3.9)$ & $6.1( \pm 5.2)$ & $<0.001^{1,2}$ \\
\hline \multicolumn{2}{|l|}{ STS score } & $8.5( \pm 8.5)$ & $2.1( \pm 1.4)$ & $3.3( \pm 3.1)$ & $<0.001^{1,2}$ \\
\hline \multirow[t]{3}{*}{ NYHA Class } & II & $37(10)$ & $29(31)$ & 87 (38) & \multirow{3}{*}{$<0.001^{1,2}$} \\
\hline & III & $268(73)$ & $50(53)$ & $112(49)$ & \\
\hline & IV & $60(16)$ & $16(17)$ & $28(12)$ & \\
\hline \multicolumn{2}{|l|}{ LVEF, \% } & $33.0( \pm 13.6)$ & $37.6( \pm 12.7)$ & $29.8( \pm 11.9)$ & $<0.001^{1,2,3}$ \\
\hline \multirow[t]{3}{*}{$\mathrm{PH}^{\pi}$} & No & $65(21)$ & $14(19)$ & $23(16)$ & \multirow{3}{*}{0.802} \\
\hline & Moderate & $178(57)$ & $46(62)$ & $92(63)$ & \\
\hline & Severe & 71 (23) & 14 (19) & $31(21)$ & \\
\hline \multicolumn{2}{|l|}{ MRgr 4/4 } & $151(68)$ & $54(57)$ & $53(23)$ & $<0.001^{2,3}$ \\
\hline \multicolumn{6}{|c|}{$\begin{array}{l}\text { Values are given as mean }\left( \pm \text { SD) or number }(\%) .{ }^{*} \text { glomerular filtration rate }<45 \mathrm{ml} / \mathrm{min} / 1.73 \mathrm{~m}^{2} .{ }^{~}{ }^{m} \text { moderate pulmonary hypertension was defined as }\right. \\
\text { systolic pulmonary artery pressure } 31 \text { to } 55 \mathrm{mmHg} \text {; severe was defined as systolic pulmonary artery pressure }>55 \mathrm{mmH} \text {. }{ }^{1} \text { post hoc significant between } \\
\text { MitraClip and Surgery. }{ }^{2} \text { post hoc significant between MitraClip and Conservative treatment. }{ }^{3} \text { post hoc significant between Surgery and Conservative } \\
\text { treatment. AF: atrial fibrillation; BMI: body mass index; CABG: coronary artery bypass graft; CAD: coronary artery disease; COPD: chronic obstructive } \\
\text { pulmonary disease; CRT: cardiac resynchronisation therapy; CVA: cerebrovascular accident or transient ischaemic attack; DM: diabetes mellitus; } \\
\text { ESII: EuroSCORE II; HT: hypertension; LES: logistic EuroSCORE; LVEF: left ventricular ejection fraction; MRgr: mitral regurgitation grade; } \\
\text { MI: myocardial infarction; NYHA: New York Heart Association; PCI: percutaneous coronary intervention; PH: pulmonary hypertension; PM: pacemaker; } \\
\text { RI: renal insufficiency; STS score: Society of Thoracic Surgeons score }\end{array}$} \\
\hline
\end{tabular}

\section{SURVIVAL}

Median follow-up of DMR patients was 2.8 (IQR 1.3-5.0) years. For MitraClip patients, follow-up was 2.0 (IQR 1.0-3.6) years. For surgically and conservatively treated patients this was 5.5 (IQR 3.4-7.3) and 3.3 (IQR 1.6-5.1) years, respectively. Fifty (30\%) of the patients who underwent MitraClip therapy died during threeyear follow-up, while 15 (23\%) surgically treated and $21(48 \%)$ conservatively treated patients died. We chose not to analyse survival differences of the treatment options for DMR, since there were only a few patients in the control groups to compare.

\section{Discussion}

In the current study we studied all-cause mortality outcomes of three treatment options for MR, within two high-risk populations diagnosed with either FMR or DMR. For both populations we found that patients treated with surgery had the lowest observed mortality, whereas conservatively treated patients were shown to have the highest mortality rate during follow-up. For patients with FMR, MitraClip was an independent predictor of reduced mortality when compared to conservative therapy, while surgery was not shown to be superior compared to MitraClip treatment in a multivariate model.

\section{FMR}

\section{MITRACLIP VS. CONSERVATIVE}

The baseline characteristics of the MitraClip cohort were similar or even worse when compared to the conservatively treated group. This may seem odd as one would expect that patients who underwent intervention, albeit minimally invasive, would have a lower risk than those merely treated with medication and/or resynchronisation therapy. A potential explanation could be that, at a time 
Table 2. Functional mitral regurgitation, predictors of mortality.

\begin{tabular}{|c|c|c|c|c|}
\hline & \multicolumn{2}{|c|}{ Univariate } & \multicolumn{2}{|c|}{ Multivariate } \\
\hline & $\begin{array}{c}\text { Hazard ratio } \\
\text { (95\% CI) }\end{array}$ & $p$-value & $\begin{array}{c}\text { Hazard ratio } \\
\text { (95\% CI) }\end{array}$ & $p$-value \\
\hline Treatment & & 0.001 & & $<0.001$ \\
\hline MitraClip & Reference & & Reference & \\
\hline Surgery & $0.57(0.36-0.90)$ & 0.015 & $0.863(0.539-1.383)$ & 0.541 \\
\hline $\begin{array}{l}\text { Conservative } \\
\text { treatment }\end{array}$ & $1.30(1.00-1.70)$ & 0.049 & 1.79 (1.34-2.39) & $<0.001$ \\
\hline Age & $1.04(1.03-1.06)$ & $<0.001$ & $1.04(1.03-1.06)$ & $<0.001$ \\
\hline Male & $1.17(0.91-1.51)$ & 0.226 & & \\
\hline BMI & $0.97(0.94-1.00)$ & 0.033 & & \\
\hline HT & $1.06(0.82-1.36)$ & 0.671 & & \\
\hline DM & $1.27(0.96-1.68)$ & 0.089 & & \\
\hline $\mathrm{AF}$ & $1.40(1.09-1.80)$ & 0.009 & & \\
\hline COPD & $1.56(1.17-2.07)$ & 0.002 & $1.60(1.20-2.13)$ & 0.001 \\
\hline CAD & $1.22(0.94-1.57)$ & 0.130 & & \\
\hline $\mathrm{Ml}$ & $1.32(1.03-1.70)$ & 0.029 & & \\
\hline $\mathrm{PCl}$ & $1.11(0.83-1.48)$ & 0.495 & & \\
\hline CABG & $1.31(1.00-1.73)$ & 0.050 & & \\
\hline CVA & $1.14(0.81-1.60)$ & 0.444 & & \\
\hline PM & $1.42(1.08-1.87)$ & 0.013 & $1.78(1.33-2.40)$ & $<0.001$ \\
\hline CRT & $1.42(0.99-2.03)$ & 0.055 & & \\
\hline $\mathrm{RI}$ & $2.03(1.55-2.66)$ & $<0.001$ & & \\
\hline LES & $1.03(1.02-1.03)$ & $<0.001$ & & \\
\hline ESII & $1.05(1.04-1.06)$ & $<0.001$ & & \\
\hline STS score & $1.04(1.03-1.06)$ & $<0.001$ & & \\
\hline NYHA Class & & $<0.001$ & & $<0.001$ \\
\hline II & Reference & & Reference & \\
\hline III & $1.46(1.02-2.08)$ & 0.038 & $1.60(1.10-2.34)$ & 0.014 \\
\hline IV & $3.17(2.11-4.76)$ & $<0.001$ & $3.43(2.25-5.24)$ & $<0.001$ \\
\hline LVEF & $1.00(0.99-1.01)$ & 0.821 & & \\
\hline $\mathrm{PH}$ & & 0.027 & & \\
\hline None & Reference & & & \\
\hline Moderate & $1.25(0.83-1.86)$ & 0.286 & & \\
\hline Severe & $1.78(1.13-2.80)$ & 0.012 & & \\
\hline MRgr 4/4 & $1.05(0.79-1.40)$ & 0.753 & & \\
\hline \multicolumn{5}{|c|}{$\begin{array}{l}\text { AF: atrial fibrillation; BMI: body mass index; CABG: coronary artery bypass graft; } \\
\text { CAD: coronary artery disease; Cl: confidence interval; COPD: chronic obstructive pulmonary } \\
\text { disease; CRT: cardiac resynchronisation therapy; CVA: cerebrovascular accident or } \\
\text { transient ischaemic attack; DM: diabetes mellitus; ESII: EuroSCORE Il; HT: hypertension; } \\
\text { LES: logistic EuroSCORE; LVEF: left ventricular ejection fraction; MRgr: mitral regurgitation } \\
\text { grade; MI: myocardial infarction; NYHA: New York Heart Association; PCI: percutaneous } \\
\text { coronary intervention; PH: pulmonary hypertension; PM: pacemaker; RI: renal insufficiency; } \\
\text { STS score: Society of Thoracic Surgeons score }\end{array}$} \\
\hline
\end{tabular}

when MitraClip was not available, high-risk patients were less likely to be referred to the cardiologist by the general practitioner since there would be no expected treatment benefit ${ }^{14,15}$. Another potential cause could be that contemporary patients are more likely to be designated to undergo MitraClip treatment instead of conservative management if there are signs of disease progression, though a recently conducted observational study showed the contrary. A significant difference in baseline MR grade $(68 \%$ MR grade 4/4 in MitraClip, compared to $23 \%$ in the conservative group) in the present study supports the latter.

Nonetheless, three previous studies comparing conservative to MitraClip therapy for patients with FMR have been published. The recently published data of the MITRA-FR randomised controlled trial, in which 152 patients were studied in both arms, showed no significant difference in all-cause mortality between the groups. The writers argue that, for FMR, the potential benefit of intervention on MR reduction might be diminished by the course of progression of heart failure. This outcome contradicts the findings of the present study. However, this trial was not powered to study mortality, and the outcome may have been influenced by the lack of MitraClip experience in the participating centres ${ }^{16}$. Giannini et al presented the results of a study involving 160 patients, in which the Kaplan-Meier survival analysis resulted in three-year mortality rates of $38.6 \%$ and $65.1 \%(\mathrm{p}=0.007)$ for the MitraClip and conservative groups, respectively ${ }^{9}$. The COAPT trial, primarily designed to study hospitalisation rates, is another recently published study which randomised between MitraClip and conservative treatments for patients with secondary MR: 302/312 patients were included for each arm and, in contrast to MITRA-FR, this study was actually also powered for secondary outcomes such as survival. The investigators found that two-year mortality for patients treated with MitraClip was $29.1 \%$ versus $46.1 \%$ for those who received conservative therapy (HR 0.62, $\mathrm{p}<0.001)^{17}$. Our present finding, that conservative treatment has an increased adjusted mortality hazard when compared to MitraClip (HR 1.79, $\mathrm{p}<0.001$ ), adds to the argument for treating patients with the latter if MV anatomy permits. One explanation for better survival among patients treated with MitraClip may be the potential positive effect of repair on left ventricle remodelling $^{18}$, since LVEF and MR grade ${ }^{19}$ are both associated with mortality. Another cause could be that patients who were treated with MitraClip received a higher standard of heart failure care through better outpatient follow-up. Also, when comparing the two recently published randomised trials ${ }^{16,17}$ and the present study, we see that there might be a correlation between pre-interventional MR grade and survival benefit of MitraClip intervention: in MITRA-FR, roughly $60 \%$ of the included MitraClip patients had MR grade 4/4; for the present study this was roughly $70 \%$. In COAPT this was roughly $50 \%$; however, their definition of grade $4 / 4$ was stricter, with both higher mean effective regurgitant orifice area and higher mean regurgitant volume. It makes sense that greater potential MR reduction by intervention may lead to greater survival benefit. Also, in MITRA-FR, MR grade reduction to $2 / 4$ or less was achieved in $91 \%$; in the present study this was $93 \%$ and for COAPT this was $95 \%$.

\section{MITRACLIP VS. SURGERY}

Despite having used similar inclusion criteria to identify high-risk patients, our surgical cohort showed markedly more favourable characteristics when compared to the MitraClip group. This is not surprising since surgical therapy for high-risk patients with FMR was not - and is not - indicated according to European guidelines, whereas MitraClip treatment of such patients may currently be 
considered (indication class $2 \mathrm{~b}$, level of evidence $\mathrm{C}$ ) ${ }^{4}$. Indeed, patient profiles from other observational studies of FMR treatment show similar discrepancies between MitraClip and surgical cohorts ${ }^{11,12,18}$. More importantly, none of these studies found a significant difference in adjusted mortality hazard. It is not surprising that our highrisk surgical cohort was probably highly selected, having a more favourable baseline profile (i.e., mean age 67.5 versus 72.8 years, $\mathrm{p}<0.001$ ), and therefore was shown to have a better survival outcome when compared to our MitraClip group. We hypothesise that, when correcting for baseline differences, the survival hazard is similar because for FMR other factors that make up this disease, such as (ischaemic) reduced LVEF, contribute more to prognosis than mitral insufficiency itself ${ }^{20}$. In other words, reducing MR by either surgical or percutaneous intervention does not entirely reverse the clinical problem at hand. This preliminary knowledge will have to be confirmed by the ongoing MATTERHORN randomised controlled trial that is expected to be completed in December 2019 (ClinicalTrials. gov Identifier: NCT02371512).

\section{DMR}

We found significant baseline differences for the studied DMR cohorts. In short, the conservatively treated patients had the highest mean age, while the MitraClip patients seemed to have the highest surgical risk scores. Unfortunately, we were not able to include significant numbers of surgically or conservatively treated patients. Such factors made us decide not to perform comparative analyses, since we did not feel that we would be able to draw fair conclusions from the results because of significant selection bias.

\section{Limitations}

For this study we retrospectively tried to form matching control groups according to high-risk characteristics such as advanced age or presence of previous cardiac surgery. Still, there were significant differences at baseline that made the inclusion criterion "high-risk" more flexible than anticipated, which may have confounded our outcomes. By using a multivariate model and propensity scoring/matching we could partially neutralise this selection bias; however, the methodology used does not control for unknown confounders. By using previously collected data, we could only study all-cause mortality outcomes. One could argue that knowledge about survival benefit is less essential for a highrisk population burdened with several quality-of-life-reducing comorbidities. Therefore, our preliminary findings should only be used as a complementary factor for decision making. For DMR, we did not perform comparative analyses between the treatment options because of significant selection bias.

\section{Conclusions}

High-risk patients with symptomatic functional mitral regurgitation seem to have reduced mortality when undergoing MitraClip intervention compared to those receiving conservative treatment. Our findings need to be supported by future randomised trials designed primarily for studying mortality outcomes.

\section{Impact on daily practice}

For functional mitral regurgitation no clear survival benefit of surgery has been shown compared to conservative treatment. The recently published MITRA-FR trial also could not show a clear survival benefit of MitraClip. However, debate continues since the COAPT trial did actually publish evidence of MitraClip superiority over conservative management. The current study supports the finding of the COAPT trial, by showing a superior survival of MitraClip patients when compared to those treated conservatively. Additionally, the present study demonstrated a non-inferiority outcome of MitraClip patients with functional mitral regurgitation compared to similar patients who underwent surgical management.

\section{Funding}

A grant from Abbott Vascular was used to maintain a MitraClip registry at the St. Antonius Hospital.

\section{Conflict of interest statement}

B.J. Van den Branden has received a speaker's fee and is a proctor for Abbott. M.J. Swaans has received personal fees from Abbott Vascular and Boston Scientific for proctoring, and from Philips Healthcare for lecturing. J. Baan Jr has received an unrestricted research grant from Abbott Vascular and is a proctor for Abbott Vascular. J.A. Van der Heyden has received a grant from Abbott. R. Schurer has received personal fees from Abbott and is an occasional proctor for Abbott Vascular. The other authors have no conflicts of interest to declare.

\section{References}

1. Enriquez-Sarano M, Akins CW, Vahanian A. Mitral regurgitation. Lancet. 2009;373:1382-94.

2. Kortlandt FA, van 't Klooster CC, Bakker AL, Swaans MJ, Kelder JC, de Kroon TL, Rensing BJ, Eefting FD, Van der Heyden JA, Post MC. The predictive value of conventional surgical risk scores for periprocedural mortality in percutaneous mitral valve repair. Neth Heart J. 2016;24:475-80.

3. Nishimura RA, Otto CM, Bonow RO, Carabello BA, Erwin JP 3rd, Fleisher LA, Jneid H, Mack MJ, McLeod CJ, O'Gara PT, Rigolin VH, Sundt TM 3rd, Thompson A. 2017 AHA/ACC Focused Update of the 2014 AHA/ACC Guideline for the Management of Patients With Valvular Heart Disease: A Report of the American College of Cardiology/American Heart Association Task Force on Practice Guidelines. J Am Coll Cardiol. 2017;70:252-89.

4. Falk V, Baumgartner H, Bax JJ, De Bonis M, Hamm C, Holm PJ, Lung B, Lancellotti P, Lansac E, Munoz DR, Rosenhek R, Sjogren J, Tornos Mas P, Vahanian A, Walther T, Wendler O, Windecker S, Zamorano JL; ESC Scientific Document Group. 2017 ESC/EACTS Guidelines for the management of valvular heart disease. Eur J Cardiothorac Surg. 2017;52:616-64.

5. Maisano F, Franzen O, Baldus S, Schafer U, Hausleiter J, Butter C, Ussia GP, Sievert H, Richardt G, Widder JD, Moccetti T, 
Schillinger W. Percutaneous mitral valve interventions in the real world: early and 1-year results from the ACCESS-EU, a prospective, multicenter, nonrandomized post-approval study of the MitraClip therapy in Europe. J Am Coll Cardiol. 2013;62:1052-61.

6. Velazquez EJ, Samad Z, Al-Khalidi HR, Sangli C, Grayburn PA, Massaro JM, Stevens SR, Feldman TE, Krucoff MW. The MitraClip and survival in patients with mitral regurgitation at high risk for surgery: A propensity-matched comparison. Am Heart J. 2015;170:1050-9.

7. Taramasso M, Maisano F, Latib A, Denti P, Buzzatti N, Cioni M, La Canna G, Colombo A, Alfieri O. Clinical outcomes of MitraClip for the treatment of functional mitral regurgitation. EuroIntervention. 2014;10:746-52.

8. Swaans MJ, Bakker AL, Alipour A, Post MC, Kelder JC, de Kroon TL, Eefting FD, Rensing BJ, Van der Heyden JA. Survival of transcatheter mitral valve repair compared with surgical and conservative treatment in high-surgical-risk patients. JACC Cardiovasc Interv. 2014;7:875-81.

9. Giannini C, Fiorelli F, De Carlo M, Guarracino F, Faggioni M, Giordano P, Spontoni P, Pieroni A, Petronio AS. Comparison of Percutaneous Mitral Valve Repair Versus Conservative Treatment in Severe Functional Mitral Regurgitation. Am J Cardiol. 2016;117:271-7.

10. Buzzatti N, Maisano F, Latib A, Taramasso M, Denti P, La Canna G, Colombo A, Alfieri O. Comparison of outcomes of percutaneous MitraClip versus surgical repair or replacement for degenerative mitral regurgitation in octogenarians. Am J Cardiol. 2015;115:487-92.

11. Conradi L, Treede H, Rudolph V, Graumüller P, Lubos E, Baldus S, Blankenberg S, Reichenspurner H. Surgical or percutaneous mitral valve repair for secondary mitral regurgitation: comparison of patient characteristics and clinical outcomes. Eur $J$ Cardiothorac Surg. 2013;44:490-6.

12. De Bonis M, Taramasso M, Lapenna E, Denti P, La Canna G, Buzzatti N, Pappalardo F, Di Giannuario G, Cioni M, Giacomini A, Alfieri O. MitraClip therapy and surgical edge-to-edge repair in patients with severe left ventricular dysfunction and secondary mitral regurgitation: mid-term results of a single-centre experience†. Eur J Cardiothorac Surg. 2016;49:255-62.

13. Kortlandt FA, Velu JF, Schurer R, Hendriks T, Van den Branden B, Bouma B, Feldman T, Kelder J, Bakker A, Post M, Van der Harst P, Eefting F, Swaans M, Rensing B, Baan J Jr, Van der Heyden J. Survival After MitraClip Treatment Compared to Surgical and Conservative Treatment for High-Surgical-Risk Patients With Mitral Regurgitation. Circ Cardiovasc Interv. 2018;11:e005985.

14. Vesely MR, Benitez RM, Robinson SW, Collins JA, Dawood MY, Gammie JS. Surgical and Transcatheter Mitral Valve
Repair for Severe Chronic Mitral Regurgitation: A Review of Clinical Indications and Patient Assessment. J Am Heart Assoc. 2015 Dec 11;4(12).

15. Bartko PE, Pavo N, Pérez-Serradilla A, Arfsten H, Neuhold S, Wurm R, Lang IM, Strunk G, Dal-Bianco JP, Levine RA, Hülsmann M, Goliasch G. Evolution of secondary mitral regurgitation. Eur Heart J Cardiovasc Imaging. 2018;19:622-9.

16. Obadia JF, Messika-Zeitoun D, Leurent G, Iung B, Bonnet G, Piriou N, Lefevre T, Piot C, Rouleau F, Carrié D, Nejjari M, Ohlmann P, Leclercq F, Saint Etienne C, Teiger E, Leroux L, Karam N, Michel N, Gilard M, Donal E, Trochu JN, Cormier B, Armoiry X, Boutitie F, Maucort-Boulch D, Barnel C, Samson G, Guerin P, Vahanian A, Mewton N; MITRA-FR Investigators. Percutaneous Repair or Medical Treatment for Secondary Mitral Regurgitation. N Engl J Med. 2018;379: 2297-306.

17. Stone GW, Lindenfeld JA, Abraham WT, Kar S, Lim DS, Mishell JM, Whisenant B, Grayburn PA, Rinaldi M, Kapadia SR, Rajagopal V, Sarembock IJ, Brieke A, Marx SO, Cohen DJ, Weissman NJ, Mack MJ; COAPT Investigators. Transcatheter Mitral-Valve Repair in Patients with Heart Failure. $N$ Engl J Med. 2018;379:2307-18.

18. Taramasso M, Denti P, Buzzatti N, De Bonis M, La Canna G, Colombo A, Alfieri O, Maisano F. Mitraclip therapy and surgical mitral repair in patients with moderate to severe left ventricular failure causing functional mitral regurgitation: a single-centre experience. Eur J Cardiothorac Surg. 2012;42:920-6.

19. Iung B, Baron G, Butchart EG, Delahaye F, GohlkeBärwolf C, Levang OW, Tornos P, Vanoverschelde JL, Vermeer F, Boersma E, Ravaud P, Vahanian A. A prospective survey of patients with valvular heart disease in Europe: The Euro Heart Survey on Valvular Heart Disease. Eur Heart J. 2003;24:1231-43.

20. Pocock S, Ariti C, McMurray J, Maggioni A, Kober L, Squire I, Swedberg K, Dobson J, Poppe K, Whalley G, Doughty RN; Meta-Analysis Global Group in Chronic Heart Failure. Predicting survival in heart failure: a risk score based on 39372 patients from 30 studies. Eur Heart J. 2013;34:1404-13.

\section{Supplementary data}

Supplementary Table 1A. MitraClip cohort.

Supplementary Table 1B. Surgical cohort.

Supplementary Table 1C. Conservative cohort.

Supplementary Table 2. Degenerative mitral regurgitation, baseline characteristics.

The supplementary data are published online at:

http://www.pcronline.com/

eurointervention/150th issue/299 


\section{Supplementary data}

Supplementary Table 1A. MitraClip cohort.

\begin{tabular}{|c|c|c|c|}
\hline Variable & FMR & DMR & $p$-value \\
\hline $\mathrm{N}$ & 365 & 165 & \\
\hline Age, years & $72.8( \pm 10.8)$ & $75.7( \pm 9.5)$ & 0.003 \\
\hline Male & $218(59.7)$ & $80(48.5)$ & 0.016 \\
\hline BMI, $\mathrm{kg} / \mathrm{m}^{2}$ & $26.0( \pm 4.3)$ & $25.8( \pm 4.3)$ & 0.565 \\
\hline HT & $168(46.0)$ & $99(60.0)$ & 0.003 \\
\hline DM & $85(23.4)$ & $39(23.6)$ & 0.943 \\
\hline AF & $204(55.9)$ & 87 (52.7) & 0.498 \\
\hline COPD & 72 (19.7) & 35 (21.2) & 0.693 \\
\hline CAD & $223(61.1)$ & $80(48.5)$ & 0.007 \\
\hline MI & $162(44.6)$ & $44(26.7)$ & $<0.001$ \\
\hline $\mathrm{PCl}$ & 115 (31.5) & $39(23.8)$ & 0.071 \\
\hline CABG & $126(34.5)$ & $37(22.4)$ & 0.005 \\
\hline CVA & 55 (15.1) & 25 (15.2) & 0.990 \\
\hline PM & $127(34.8)$ & $6(3.6)$ & $<0.001$ \\
\hline CRT & $62(17.0)$ & $13(7.9)$ & 0.005 \\
\hline $\mathbf{R I}^{\star}$ & $132(36.8)$ & $70(44.0)$ & 0.119 \\
\hline LES & $21.6( \pm 15.3)$ & $17.7( \pm 12.0)$ & 0.002 \\
\hline ESII & $8.9( \pm 7.8)$ & $6.4( \pm 5.7)$ & $<0.001$ \\
\hline STS score & $8.5( \pm 8.5)$ & $6.4( \pm 7.0)$ & 0.003 \\
\hline $\begin{array}{l}\text { NYHA } \\
\text { Class }\end{array}$ & & & 0.017 \\
\hline II & $37(10.1)$ & $35(21.2)$ & \\
\hline III & $268(73.4)$ & $105(63.6)$ & \\
\hline IV & $60(16.4)$ & $25(15.2)$ & \\
\hline LVEF, \% & $34.0( \pm 13.6)$ & $43.7( \pm 15.0)$ & $<0.001$ \\
\hline $\mathrm{PH} \dagger$ & & & 0.597 \\
\hline No & 65 (20.7) & 24 (16.9) & \\
\hline Moderate & $178(56.7)$ & 96 (67.6) & \\
\hline Severe & 71 (22.6) & $22(15.5)$ & \\
\hline
\end{tabular}




\begin{tabular}{|l|l|l|l|}
\hline MRgr 4/4 & $151(68.3)$ & $93(66.9)$ & 0.779 \\
\hline
\end{tabular}

Values are given as mean ( \pm SD) or number $(\%)$.

${ }^{*}$ glomerular filtration rate $<45 \mathrm{ml} / \mathrm{min} / 1.73 \mathrm{~m}^{2}$.

† moderate pulmonary hypertension was defined as systolic pulmonary artery pressure 31 to 55 $\mathrm{mmHg}$; severe was defined as systolic pulmonary artery pressure $>55 \mathrm{mmHg}$.

AF: atrial fibrillation; BMI: body mass index; CABG: coronary artery bypass graft; $C A D$ : coronary artery disease; COPD: chronic obstructive pulmonary disease; CRT: cardiac resynchronisation therapy; CVA: cerebrovascular accident or transient ischaemic attack; DM: diabetes mellitus; DMR: degenerative mitral regurgitation; ESII: EuroSCORE II; FMR: functional mitral regurgitation; HT: hypertension; LES: logistic EuroSCORE; LVEF: left ventricular ejection fraction; MI: myocardial infarction; MRgr: mitral regurgitation grade; NYHA: New York Heart Association; PCI: percutaneous coronary intervention; PH: pulmonary hypertension; PM: pacemaker; RI: renal insufficiency; STS score: Society of Thoracic Surgeons score 
Supplementary Table 1B. Surgical cohort.

\begin{tabular}{|c|c|c|c|}
\hline Variable & FMR & DMR & $p$-value \\
\hline $\mathrm{N}$ & 95 & 66 & \\
\hline Age, years & $67.5( \pm 9.4)$ & $71.4( \pm 10.5)$ & 0.016 \\
\hline Male & $48(50.5)$ & $40(60.6)$ & 0.208 \\
\hline BMI, $\mathbf{k g} / \mathrm{m}^{2}$ & $27.5( \pm 5.3)$ & $26.9( \pm 4.9)$ & 0.465 \\
\hline HT & $57(60.6)$ & $22(33.3)$ & 0.001 \\
\hline DM & $29(30.5)$ & $11(16.7)$ & 0.046 \\
\hline AF & $35(36.8)$ & $33(50.0)$ & 0.097 \\
\hline COPD & $18(18.9)$ & $19(28.8)$ & 0.146 \\
\hline CAD & $46(48.4)$ & $18(27.3)$ & 0.007 \\
\hline MI & $25(26.3)$ & $9(13.6)$ & 0.053 \\
\hline $\mathrm{PCl}$ & $11(11.6)$ & $7(10.6)$ & 0.848 \\
\hline CABG & $14(14.7)$ & $5(7.6)$ & 0.167 \\
\hline CVA & $7(7.4)$ & $11(17.5)$ & 0.054 \\
\hline PM & $11(11.6)$ & $6(9.1)$ & 0.614 \\
\hline CRT & $1(1.1)$ & 0 & 0.405 \\
\hline $\mathbf{R \mathbf { I } ^ { \star }}$ & $11(13.4)$ & $10(17.9)$ & 0.477 \\
\hline LES & $12.2( \pm 8.5)$ & $10.0( \pm 7.6)$ & 0.089 \\
\hline ESII & $4.7( \pm 3.9)$ & $3.8( \pm 3.7)$ & 0.111 \\
\hline STS score & $2.1( \pm 1.4)$ & $3.4( \pm 5.2)$ & 0.054 \\
\hline $\begin{array}{l}\text { NYHA } \\
\text { Class }\end{array}$ & & & 0.652 \\
\hline II & $29(30.5)$ & $22(33.3)$ & \\
\hline III & $50(52.6)$ & $27(40.9)$ & \\
\hline IV & $16(16.8)$ & $17(25.8)$ & \\
\hline LVEF, \% & $37.6( \pm 12.7)$ & $54.1( \pm 9.0)$ & $<0.001$ \\
\hline PH† & & & 0.599 \\
\hline No & $14(18.9)$ & $13(26.5)$ & \\
\hline Moderate & $46(62.2)$ & $26(53.1)$ & \\
\hline Severe & 14 (18.9) & $10(20.4)$ & \\
\hline
\end{tabular}




\begin{tabular}{|l|l|l|l|}
\hline MRgr 4/4 & $54(56.8)$ & $45(68.2)$ & 0.147 \\
\hline
\end{tabular}

Values are given as mean $( \pm S D)$ or number $(\%)$.

* glomerular filtration rate $<45 \mathrm{ml} / \mathrm{min} / 1.73 \mathrm{~m}^{2}$.

$\dagger$ moderate pulmonary hypertension was defined as systolic pulmonary artery pressure 31 to 55 $\mathrm{mmHg}$; severe was defined as systolic pulmonary artery pressure $>55 \mathrm{mmHg}$.

AF: atrial fibrillation; BMI: body mass index; CABG: coronary artery bypass graft; $C A D$ : coronary artery disease; COPD: chronic obstructive pulmonary disease; CRT: cardiac resynchronisation therapy; CVA: cerebrovascular accident or transient ischaemic attack; DM: diabetes mellitus; DMR: degenerative mitral regurgitation; ESII: EuroSCORE II; FMR: functional mitral regurgitation; HT: hypertension; LES: logistic EuroSCORE; LVEF: left ventricular ejection fraction; MI: myocardial infarction; MRgr: mitral regurgitation grade; NYHA: New York Heart Association; PCl: percutaneous coronary intervention; PH: pulmonary hypertension; PM: pacemaker; RI: renal insufficiency; STS score: Society of Thoracic Surgeons score 
Supplementary Table 1C. Conservative cohort.

\begin{tabular}{|c|c|c|c|}
\hline Variable & FMR & DMR & $p$-value \\
\hline $\mathrm{N}$ & 228 & 44 & \\
\hline Age, years & $72.6( \pm 11.9)$ & $80.8( \pm 7.9)$ & $<0.001$ \\
\hline Male & $127(55.7)$ & 17 (38.6) & 0.038 \\
\hline BMI, $\mathbf{k g} / \mathrm{m}^{2}$ & $26.0( \pm 4.4)$ & $26.4( \pm 6.2)$ & 0.781 \\
\hline HT & $97(42.7)$ & $23(52.3)$ & 0.244 \\
\hline DM & $53(23.6)$ & $9(20.5)$ & 0.656 \\
\hline AF & $87(38.8)$ & $26(59.1)$ & 0.013 \\
\hline COPD & 49 (21.9) & $6(13.6)$ & 0.217 \\
\hline CAD & $110(48.7)$ & $11(25.0)$ & 0.004 \\
\hline MI & 76 (33.6) & $5(11.4)$ & 0.003 \\
\hline $\mathbf{P C l}$ & $33(14.7)$ & $4(9.1)$ & 0.322 \\
\hline CABG & 35 (15.6) & 7 (15.9) & 0.953 \\
\hline CVA & 39 (17.3) & $10(22.7)$ & 0.397 \\
\hline PM & $25(11.1)$ & $5(11.4)$ & 0.954 \\
\hline CRT & $10(4.4)$ & 0 & 0.155 \\
\hline $\mathbf{R \mathbf { I } ^ { * }}$ & $54(32.1)$ & $11(29.7)$ & 0.776 \\
\hline LES & $19.4( \pm 14.2)$ & $15.3( \pm 8.3)$ & 0.009 \\
\hline ESII & $6.1( \pm 5.2)$ & $4.4( \pm 3.4)$ & 0.009 \\
\hline STS score & $3.3( \pm 3.1)$ & $4.0( \pm 2.8)$ & 0.211 \\
\hline $\begin{array}{l}\text { NYHA } \\
\text { Class }\end{array}$ & & & 0.690 \\
\hline II & 87 (38.3) & $19(43.2)$ & \\
\hline III & $112(49.3)$ & $19(43.2)$ & \\
\hline IV & $28(12.3)$ & $6(13.6)$ & \\
\hline LVEF, \% & $29.6( \pm 11.6)$ & $52.8( \pm 8.9)$ & $<0.001$ \\
\hline PH† & & & 0.858 \\
\hline No & $23(15.8)$ & $3(12.0)$ & \\
\hline Moderate & $92(63.0)$ & $17(68.0)$ & \\
\hline Severe & $31(21.2)$ & $5(20.0)$ & \\
\hline MRgr 4/4 & $53(23.3)$ & $12(27.3)$ & 0.578 \\
\hline
\end{tabular}

Values are given as mean $( \pm S D)$ or number $(\%)$. 
* glomerular filtration rate $<45 \mathrm{ml} / \mathrm{min} / 1.73 \mathrm{~m}^{2}$.

† moderate pulmonary hypertension was defined as systolic pulmonary artery pressure 31 to 55 $\mathrm{mmHg}$; severe was defined as systolic pulmonary artery pressure $>55 \mathrm{mmHg}$.

AF: atrial fibrillation; BMI: body mass index; CABG: coronary artery bypass graft; CAD: coronary artery disease; COPD: chronic obstructive pulmonary disease; CRT: cardiac resynchronisation therapy; CVA: cerebrovascular accident or transient ischaemic attack; DM: diabetes mellitus; DMR: degenerative mitral regurgitation; ESII: EuroSCORE II; FMR: functional mitral regurgitation; HT: hypertension; LES: logistic EuroSCORE; LVEF: left ventricular ejection fraction; MI: myocardial infarction; MRgr: mitral regurgitation grade; NYHA: New York Heart Association; PCI: percutaneous coronary intervention; PH: pulmonary hypertension; PM: pacemaker; RI: renal insufficiency; STS score: Society of Thoracic Surgeons score 
Supplementary Table 2. Degenerative mitral regurgitation, baseline characteristics.

\begin{tabular}{|c|c|c|c|c|}
\hline Variable & MitraClip & Surgery & Conservative treatment & $p$-value \\
\hline $\mathrm{N}$ & 165 & 66 & 44 & \\
\hline Age, years & $75.7( \pm 9.5)$ & $71.4( \pm 10.5)$ & $80.8( \pm 7.9)$ & $<0.001^{1,2,3}$ \\
\hline Male & $80(49)$ & $40(61)$ & $17(39)$ & 0.068 \\
\hline BMI, $\mathbf{k g} / \mathbf{m}^{2}$ & $25.8( \pm 4.3)$ & $26.9( \pm 4.9)$ & $26.4( \pm 6.2)$ & 0.287 \\
\hline HT & $99(60)$ & $22(33)$ & $23(52)$ & $0.001^{1}$ \\
\hline DM & $39(24)$ & $11(17)$ & $9(21)$ & 0.499 \\
\hline $\mathbf{A F}$ & $87(53)$ & $33(50)$ & $26(59)$ & 0.638 \\
\hline COPD & $35(21)$ & $19(29)$ & $6(14)$ & 0.162 \\
\hline CAD & $80(49)$ & $18(27)$ & $11(25)$ & $0.001^{1,2}$ \\
\hline MI & $44(27)$ & $9(14)$ & $5(11)$ & 0.020 \\
\hline $\mathrm{PCl}$ & $39(24)$ & $7(11)$ & $4(9)$ & 0.015 \\
\hline CABG & $37(22)$ & $5(8)$ & $7(16)$ & $0.027^{1}$ \\
\hline CVA & $25(15)$ & $11(18)$ & $10(23)$ & 0.488 \\
\hline PM & $6(4)$ & $6(9)$ & $5(11)$ & 0.089 \\
\hline CRT & $13(8)$ & 0 & 0 & 0.011 \\
\hline $\mathbf{R \mathbf { I } ^ { * }}$ & $70(44)$ & $10(18)$ & $11(30)$ & $0.001^{1}$ \\
\hline LES & $17.7( \pm 12.0)$ & $10.0( \pm 7.6)$ & $15.3( \pm 8.3)$ & $<0.001^{1,3}$ \\
\hline ESII & $6.5( \pm 5.7)$ & $3.8( \pm 3.8)$ & $4.4( \pm 3.4)$ & $<0.001^{1,2}$ \\
\hline STS score & $6.4( \pm 7.0)$ & $3.4( \pm 5.2)$ & $4.0( \pm 2.8)$ & $0.001^{1}$ \\
\hline $\begin{array}{l}\text { NYHA } \\
\text { Class }\end{array}$ & & & & 0.090 \\
\hline II & $35(21)$ & $22(33)$ & $19(43)$ & \\
\hline III & $105(64)$ & $27(41)$ & $19(43)$ & \\
\hline IV & $25(15)$ & $17(26)$ & $6(14)$ & \\
\hline LVEF, \% & $43.7( \pm 15.0)$ & $54.1( \pm 9.0)$ & $52.8( \pm 8.9)$ & $<0.001^{1,2}$ \\
\hline PH† & & & & 0.625 \\
\hline No & $24(17)$ & $13(27)$ & $3(12)$ & \\
\hline Moderate & $96(68)$ & $26(53)$ & $17(68)$ & \\
\hline Severe & $22(16)$ & $10(20)$ & $5(20)$ & \\
\hline MRgr 4/4 & $93(67)$ & $45(68)$ & $12(27)$ & $<0.001^{1,2,3}$ \\
\hline
\end{tabular}

Values are given as mean ( \pm SD) or number (\%). 
* glomerular filtration rate $<45 \mathrm{ml} / \mathrm{min} / 1.73 \mathrm{~m}^{2}$.

† moderate pulmonary hypertension was defined as systolic pulmonary artery pressure 31 to 55 $\mathrm{mmHg}$; severe was defined as systolic pulmonary artery pressure $>55 \mathrm{mmHg}$.

${ }^{1}$ post hoc significant between MitraClip and Surgery.

${ }^{2}$ post hoc significant between MitraClip and Conservative treatment.

${ }^{3}$ post hoc significant between Surgery and Conservative treatment.

AF: atrial fibrillation; BMI: body mass index; CABG: coronary artery bypass graft; CAD: coronary artery disease; COPD: chronic obstructive pulmonary disease; CRT: cardiac resynchronisation therapy; CVA: cerebrovascular accident or transient ischaemic attack; DM: diabetes mellitus; DMR: degenerative mitral regurgitation; ESII: EuroSCORE II; FMR: functional mitral regurgitation; HT: hypertension; LES: logistic EuroSCORE; LVEF: left ventricular ejection fraction; MI: myocardial infarction; MRgr: mitral regurgitation grade; NYHA: New York Heart Association; PCI: percutaneous coronary intervention; PH: pulmonary hypertension; PM: pacemaker; RI: renal insufficiency; STS score: Society of Thoracic Surgeons score 